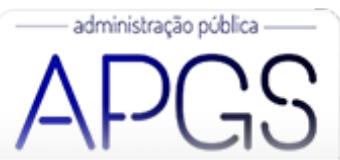

Administração Pública e Gestão Social ISSN: 2175-5787

apgs@ufv.br

Universidade Federal de Viçosa

Brasil

\title{
Transparência e Dados Abertos Governamentais: Possibilidades e Desafios a Partir da Lei De Acesso À Informação
}

Possamai, Ana Júlia; Gonzatti de Souza, Vitoria

Transparência e Dados Abertos Governamentais: Possibilidades e Desafios a Partir da Lei De Acesso À

Informação

Administração Pública e Gestão Social, vol. 12, núm. 2, 2020

Universidade Federal de Viçosa, Brasil

Disponible en: http://www.redalyc.org/articulo.oa?id=351562414012

Esta obra está bajo una Licencia Creative Commons Atribución-NoComercial-SinDerivar 3.0 Internacional. 


\title{
Transparência e Dados Abertos Governamentais: Possibilidades e Desafios a Partir da
} Lei De Acesso À Informação

\author{
Transparency and open Government Data: Possibilities and Challenges Based on the Access to Information Law \\ Transparencia y Datos Abiertos Gubernamentales: Posibilidades y Desafíos a Partir de la ley de Acceso a la \\ Información
}

Ana Júlia Possamai

Fundação de Economia e Estatística Siegfried Emanuel

Redalyc: http://www.redalyc.org/articulo.oa?

Heuser, Brasil

anajulia.possamai@gmail.com

Vitoria Gonzatti de Souza

Universidade Federal do Rio Grande do Sul, Brasil

vitoriagonzatti@live.com

id $=351562414012$

Recepción: 16 Abril 2018

Aprobación: 28 Enero 2019

Publicación: 01 Abril 2020

\section{Resumo:}

O paradigma dos dados abertos vem ganhando espaço na gestão pública, tendo sido incorporado ao direito de acesso à informação, componente fundamental das poliarquias. $\mathrm{O}$ artigo objetiva analisar as possibilidades e os desafios institucionais à implementação desse paradigma no Brasil, com base na Lei de Acesso à Informação. Além da análise normativa, realiza-se um estudo de caso do Governo Federal, aplicando-se técnicas de análise de conteúdo para verificar empiricamente o tratamento dispensado em primeira e última instância a solicitações de abertura de dados protocoladas junto ao Sistema Eletrônico do Serviço de Informações ao Cidadão (e-SIC) em períodos anteriores e posteriores à edição da Política de Dados Abertos, em 2016. Os resultados demonstram amparo legal para solicitações de dados abertos governamentais, dificultadas, contudo, por espaço "cinzento" criado pelas hipóteses infralegais de restrição de acesso à informação, o que impõem alerta quanto à efetividade da nova Política.

Palavras-Chave: Dados Abertos, Governo Aberto, Direito à Informação.

\section{Abstract:}

The open data paradigm has been gaining ground in public management and it has been incorporated into the right to access to information, which is a fundamental component of polyarchies. The article aims to analyze the institutional possibilities and challenges to the implementation of this paradigm in Brazil, based on the Law of Access to Information. Normative analysis is carried out, as well as a case study of the Federal Government, where content analysis techniques are employed to empirically verify the treatment dispensed in the first and last instance to requests to open data filed with the Electronic Service System Citizen Information (e-SIC), in periods before and after the publication of the Open Data Policy, in 2016. The results demonstrate legal support for open government data requests. However, they are hampered by a "gray" area created by the infralegal hypotheses of restriction to access to information, which imposes a warning on the effectiveness of the new Open Data Policy.

KEYWORDS: Open Data, Open Government, Right to Information.

\section{Resumen:}

El paradigma de los datos abiertos viene ganando espacio en la gestión pública, habiendo sido incorporado al derecho de acceso a la información, componente fundamental de las poliarquías. El artículo objetiva analizar las posibilidades y los desafíos institucionales a la implementación de ese paradigma en Brasil, con base en la Ley de Acceso a la Información. Además del análisis normativo, se realiza un estudio de caso del Gobierno Federal, aplicándose técnicas de análisis de contenido para verificar empíricamente el tratamiento dispensado en primera y última instancia a solicitudes de apertura de datos protocoladas junto al Sistema Electrónico del Servicio de Informaciones en los períodos anteriores y posteriores a la edición de la Política de Datos Abiertos, en 2016. Los resultados demuestran amparo legal para solicitudes de datos abiertos gubernamentales, dificultadas, sin embargo, por un espacio 
"gris" creado por las hipótesis infralegales de restricción de acceso a la información, lo que impone alerta en cuanto a la efectividad de la nueva Política.

Palabras Clave: Datos abiertos, Gobierno abierto, Derecho a la información.

\section{INTRODUÇÃo}

O paradigma dos dados abertos governamentais (open government data [OGD]) vem ganhando espaço na agenda da gestão pública brasileira, especialmente a partir do protagonismo desempenhado pelo país na Open Government Partnership, em 2011. Na ocasião, ao lado de outros sete países, o Brasil assumiu compromissos nos campos da participação, da colaboração, do combate à corrupção e da transparência, contando para tanto com o suporte das novas Tecnologias de Informação e Comunicação (TIC). Como resultado imediato dessa participação, foi finalmente aprovada a Lei de Acesso à Informação - LAI (Lei n 12.527/2011) -, que regulou o direito de acesso à informação previsto na Constituição Federal de 1988. Além disso, em 2012, foi criado o Portal Brasileiro de Dados Abertos, que conta com mais de seis mil conjuntos de dados ${ }^{[\mathrm{i}]}$.

A LAI foi pioneira no mundo a incorporar o paradigma dos OGD no âmbito do direito à informação (Batista, Silva, \& Miranda, 2013). Contudo, foi com a publicação do Decreto no 8.777/2016, que editou a Política de Dados Abertos do Poder Executivo Federal, que a questão foi efetivamente elevada na agenda governamental. Além de organizar o planejamento e priorizar a abertura de determinados conjuntos de dados, a Política incluiu a possibilidade de pedido de abertura de base de dados por meio dos mesmos procedimentos de solicitação de acesso à informação criados pela lei federal.

Por dados abertos governamentais entendem-se os dados públicos, produzidos, coletados ou custodiados por órgãos estatais e disponibilizados na web em formato aberto (não proprietário), estruturado e compreensível logicamente por máquina, de modo que qualquer um possa livremente acessar, reutilizar, modificar e redistribuir para quaisquer finalidades, estando sujeito a, no máximo, exigências de creditar a sua autoria e compartilhar sob a mesma licença (World Wide Web Consortium, 2009; OpenGovData, 2007). Potencialmente, a publicação, o acesso e a reutilização de OGD estão associados à maior transparência, controle social, participação, gestão e colaboração governo-sociedade, em um processo de retroalimentação que aponta para o fortalecimento da democracia e da capacidade estatal .

Em virtude dos benefícios potenciais da abertura de dados para a gestão pública - e para a república (Bobbio, 1987) -, interessa investigar quais as condições para a institucionalização dos dados abertos governamentais no Brasil. Objetiva-se, especificamente, compreender as normas legais que versam sobre o direito de acesso à informação no país, identificando as possibilidades e os desafios que a regulamentação desses dispositivos criam à implementação do paradigma. Para além dos aspectos legais, objetiva-se verificar empiricamente esses aspectos a partir de estudo de caso do Governo Federal, investigando o tratamento efetivamente dispensado em primeira e última instância a pedidos de abertura de dados protocoladas no Sistema Eletrônico do Serviço de Informações ao Cidadão (e-SIC) em períodos anteriores e posteriores à edição da Política de Dados Abertos, em 2016. Ao verificar na prática o efeito da institucionalidade vigente sobre a adoção do paradigma dos dados abertos, busca-se não só discutir o status da temática na Administração Pública Federal (APF), mas também pautar os rumos dos avanços e dos obstáculos à realização da agenda da transparência pública na era digital.

$\mathrm{O}$ artigo está estruturado em cinco seções, além desta introdução. Na segunda seção, aborda-se a interface existente entre o direito de acesso à informação e os dados abertos governamentais. Em seguida, a partir do estudo da Lei de Acesso à Informação, identificam-se os dispositivos que amparam a abertura de dados públicos no Brasil. Na seção seguinte, por sua vez, analisam-se os empecilhos potenciais identificados nas hipóteses legais e infralegais de restrição de acesso à informação. Com base nesses parâmetros, por fim, verifica-se o tratamento dispensado pelos órgãos federais aos pedidos de dados em formatos, agregação (ou 
desagregação) ou estrutura compatíveis com a definição de OGD. A conclusão retoma alguns aspectos trabalhados e os resultados alcançados.

\section{Democracia, ACESSo À INFORMAÇÃo E DADOS ABERTOS}

O livre acesso e compartilhamento de informações sobre as atividades governamentais são requisitos institucionais mínimos de qualquer poliarquia. A informação consiste em insumo fundamental para o exercício do entendimento esclarecido e da participação efetiva na formação das preferências (Dahl, 2012). Afinal, conforme pontuam Zuccolotto e Teixeira (2015, p. 84), "sem informações confiáveis, relevantes e oportunas, não há possibilidade de os atores políticos ativarem os mecanismos de responsabilização”, engrenagens principais da democracia.

No âmbito dos esforços que visam hoje fortalecer esses mecanismos, destaca-se a Open Government Partnership, iniciativa internacional que busca difundir e incentivar práticas governamentais relacionadas à transparência, ao acesso à informação pública e à participação social. O paradigma dos dados abertos está intrinsecamente vinculado a essas medidas, visto que compartilha do objetivo de ampliar a disponibilidade e a reutilização de informações públicas para fins de evidenciação sobre as ações e os problemas públicos (Janssen, 2012; Gigler, Custer, \& Rahemtulla, 2011).

A evidenciação consiste na possibilidade de realizar inferências (Laporte, Demchak, \& Friis, 2000). Para tanto, em se tratando de informações públicas cada vez mais armazenadas digitalmente, importa não só a sua disponibilização, mas também a estrutura e o formato da base digital em que as mesmas estão registradas. Se a informação é pública e lhes é propriedade de direito (Peled \& Rabin, 2011), não se pode exigir que o cidadão arque com os custos de utilizar uma solução proprietária (por exemplo, o uso do pacote Microsoft Office) para ter assegurada uma garantia fundamental (exemplo: Acesso à memória da reunião de um determinado conselho). Logo, a publicação de dados abertos governamentais atende ao requisito de evidenciação e amplia as possibilidades de exercício do entendimento esclarecido (Dahl, 2012), pois assegura condições materiais (digitais) e legais para acessar, combinar, analisar e reutilizar dados governamentais a fim de verificar, esclarecer, fiscalizar e acompanhar questões públicas variadas, de maneira continuada - e não apenas a cada ciclo eleitoral (Diniz \& Guimarães, 2013; Access Info, 2011).

A despeito das sinergias, há também diferenças nas abordagens e estratégias vinculadas à defesa e à promoção do direito de acesso à informação pública, por um lado, e dos dados abertos, por outro. Em especial, a primeira busca garantir o acesso a informações qualitativas e quantitativas, armazenadas em documentos, atas, memórias, relatórios, etc., independente do formato em que se encontram (Gigler, Custer, \& Rahemtulla, 2011). Sua defesa reside no exercício de um direito (fundamental) per se, mas também instrumental para a realização de outros direitos, tais como o direito à liberdade de expressão, opinião e participação informada (Dahl, 2012; Janssen, 2012; Cepik, 2000). O paradigma dos OGD, por sua vez, reivindica atenção não só ao acesso a informações públicas, mas também aos aspectos técnicos e legais associados à utilização (ou reutilização) dessas informações. Assim, busca-se assegurar a todos os membros da sociedade condições mínimas para aproveitar (ou reaproveitar) o valor social, político e econômico inerente às informações públicas geradas e coletadas pelo Estado, sem restrição (Janssen, 2012; Yu \& Robinson, 2012; Access Info, 2011; Gigler, Custer, \& Rahemtulla, 2011).

A contribuição dos OGD para a transparência tampouco é consenso entre especialistas. Yu e Robinson (2012) questionam as vantagens dos dados abertos para a gestão, a deliberação e a alocação de recursos, bem como sobre os resultados das políticas públicas. Para os autores, a ênfase nos OGD ofusca o propósito original da dimensão transparência no âmbito do Governo Aberto, qual seja: a prestação de conta e a responsabilização dos agentes públicos e políticos (accountability). Os autores contendem que cada prática pode existir sem a outra. Por um lado, um governo poderia ser transparente sem necessariamente fazer uso de TICs. Por outro lado, um governo poderia fornecer dados abertos apenas sobre tópicos 
práticos e politicamente neutros (tais como tabelas de horários de ônibus, calendário escolar, indicadores epidemiológicos, etc.), permanecendo de resto "opaco" e avesso a medidas mais amplas para viabilizar o controle social e a prestação de contas. Neste caso, a abertura de alguns dados governamentais serviria apenas para aplacar o apetite da sociedade por mais transparência, sem avançar na direção da accountability pública (Yu \& Robinson, 2012).

Embora à primeira vista convincente, este argumento é contestado por Weinstein e Goldstein (2012). Em primeiro lugar, os autores listam evidências de que experiências iniciais de abertura de dados (ainda que de natureza incontroversa e não política) estimularam a demanda de abertura de outros conjuntos de dados, seja para criar novos produtos e serviços, seja para fiscalizar ações e políticas e exercer o controle social. Segundo Gomes (2017), os dados abertos são antes uma prescrição normativa, segundo o qual governos democráticos devem abrir os dados que o Estado reúne e estoca. Naturalmente, nem todos esses dados tratam do comportamento de agentes públicos ou do andamento de ações ou políticas públicas e, portanto, nem tudo servirá para a transparência pública e para produzir o que o autor chama de um "olhar heterônomo" sobre quem toma decisões “em nome do povo". Porém, "tudo é dado público que pode servir aos cidadãos e às organizações para melhorar a vida de todos” (Gomes, 2017, p. 22).

Em segundo lugar, Weinstein e Goldstein (2012) argumentam que o processo de planejamento da abertura envolve não só a publicação de dados na internet, mas também uma reorientação na gestão da informação por parte das burocracias. Isso porque requer a prévia organização, estruturação, formatação, limpeza e anonimização dos dados, a fim de atender aos requisitos mínimos de abertura não só dos conjuntos de dados a serem proativamente publicados, mas também dos que vierem a ser demandados via serviços de acesso à informação. Conforme os autores, essa mudança em relação à gestão da informação conduziria à percepção de que quanto maior o valor dos dados, mais adaptáveis eles são à utilização (ou reutilização) diversa do fim para o qual foram originalmente produzidos, coletados e (ou) trabalhados na rotina governamental. No médio prazo, esta percepção conduziria à institucionalização do compromisso com a abertura (de maneira ampliada). Evidentemente, o paradigma dos dados abertos não conduzirá a uma maior accountabiliy real se requisitos mínimos de liberdades civis e direitos políticos não estiverem presentes (Peixoto, 2013).

Havendo sinergias ou divergências, no caso brasileiro, as trajetórias recentes de ambos os movimentos se retroalimentam. O direito de acesso à informação foi assegurado ainda em 1998 na Constituição Federal. Porém, somente viria a ser regulado em 2011, com a edição da Lei n ${ }^{\circ} 12.527$. Sob inspiração da Open Government Partnership, a LAI tornou-se a primeira norma de acesso à informação no mundo a incorporar à dimensão da transparência o paradigma dos dados abertos.

\section{Lei de Acesso À Informação (LAI) E dAdos abertos: Possibilidades}

A Lei de Acesso à Informação regula o acesso às informações contidas em registros ou documentos (físicos ou eletrônicos), produzidos ou acumulados por órgãos ou entidades públicos, bem como informações produzidas ou custodiadas por pessoa física ou entidade privada decorrente de qualquer vínculo com o setor público. A norma definiu os procedimentos formais para protocolar-se uma solicitação de informações, bem como as sanções em caso de seu descumprimento. Desta forma, o que até então era realizado de maneira informal, estando seu atendimento sujeito à discricionariedade do agente público, passou a ser realizado por meio da criação de um serviço de acesso à informação (SICs), operável por qualquer meio legítimo (físico ou eletrônico), compondo a chamada transparência passiva (Zuccolotto, Teixeira, \& Riccio, 2015).

A LAI também estabeleceu o dever de todos os órgãos divulgarem na internet um rol mínimo de informações, de interesse coletivo ou geral, independentemente de solicitação, ao que se convencionou chamar transparência ativa (Zuccolotto, Teixeira, \& Riccio, 2015). São informações mínimas a constar, por exemplo: Competências e estrutura organizacional; endereços, telefones e horários de atendimento ao público; despesas, repasses ou transferências de recursos financeiros, entre outras. 
Ao dispor sobre os requisitos para a publicação dessas informações nos sítios eletrônicos oficiais, a LAI foi pioneira no mundo em incorporar explicitamente o paradigma dos OGD, ao estabelecer o dever do órgão "Art. $8^{\circ}, \$ 3^{\circ}$, III - possibilitar a gravação de relatórios em diversos formatos eletrônicos, inclusive abertos e não proprietários” (Batista, Silva, \& Miranda, 2013). Conquanto, considerando os oito princípios convencionados em 2007 por um grupo de especialistas (OpenGovData, 2007), os requisitos dos dados abertos governamentais vão além do padrão tecnológico adotado para seu registro. A partir da análise normativa da LAI e dos seus manuais de implementação (Manual da Lei de Acesso à Informação para Estados e Municípios, 2013;; Aplicação da Lei de Acesso à Informação em recursos da CGU, 2015), bem como do estudo dos elementos constitutivos do conceito “aberto" (OpenGovData, 2007), indentificam-se no mínimo outros 17 dispositivos na lei federal que fazem referência ao paradigma, o que amplia as possibilidades de suas institucionalização no quadro normativo vigente. $\mathrm{O} Q$ uadro 1 classifica esses dispositivos conforme sua correspondência com os oito princípios de open data. 


\section{Quadro 1 - Os 8 Princípios dos Dados Abertos e a Lei de Acesso a Informação}

PRINCÍPIO

1. COMPLETOS: Todos os dados públicos devem ser

disponibilizados e não apenas aqueles que as autoridades julgarem pertinentes, a menos que a restrição seja regulada por estatuto e publicamente justificada.

2. PRIMÁRIOS: OS dados Sã̃o préprocessados, sem agregação ou modificação, à exceçăo do necessário para proteger dados pessoais ou outros sigilos regulados por estatuto e publicamente justificados.

3. ATUAIS: $O$ dados são publicados periodicamente e tão rapidamente quanto o necessário para preservar seu valor e utilidade.

4. ACESSIVIEIS: OS dados são disponibilizados gratuitamente, para alcançar o maior número possivel de usuários e o maior conjunto possivel de finalidades e propósitos, sem restrições.

\section{COMPREENSÍVEIS POR} MÁQUINA: OS dados são razoavelmente estruturados, possibilitando seu processamento automatizado, a custos razoavelmente baixos.

6. NÃO DISCRIMINATÓRIOS: OS dados estão disponiveis para todos, sem exigência nem necessidade de qualquer outro procedimento que impeça ou dificulte seu acesso.

\section{NÃO PROPRIETÁRIOS: OS} dados não estão sob o controle exclusivo de nenhuma entidade, tampouco estão sob um formato cuja ferramenta de decodificação controlada exclusivamente por uma organização.

8. LIVRES DE LICENÇA: Os dados não estão sujeitos a regulações de direitos autorais, marcas, patentes ou segredo industrial. Restrições razoáveis de privacidade, segurança, controle de acesso e outros privilégios são aceitas, desde que transparentes, bem justificadas e reguladas por estatutos.
PREVISÃO NA LEI DE ACESSO A INFORMAÇÃO

Art. $3^{\circ}$, I - Observância da publicidade como

preceito geral e do sigilo como exceção. Art. $7^{\circ}$, II

- Direito de obter informação contida em registros ou documentos, produzidos ou acumulados por órgãos públicos, recolhidos ou não a arquivos públicos. Art. $7^{\circ}$, III - Direito de obter informaçấo produzida ou custodiada por pessoa física ou entidade privada decorrente de qualquer vínculo. Art. $7^{\circ}, 82^{\circ}$ - Quando não autorizado acesso integral à informação, direito de obter acesso à parte não sigilosa

Art. $7^{\circ}$, IV - Direito de obter informação primária, integra, autêntica e atualizada. Art. 31 -

Tratamento das informações pessoais de forma transparente e com respeito à intimidade, vida privada, honra e imagem das pessoas, bem como às liberdades e garantias individuais.

Art. $7^{\circ}$, IV - Informação primária, integra,

autêntica e atualizada Art. $8^{\circ}, 82^{\circ}$ - Dever dos órgãos a divulgação de informaçōes em local de fácil acesso, incluindo sítios oficiais da rede mundial de computadores. Art. $8^{\circ}, 83^{\circ}$, VI - Sítios oficiais deverão manter atualizadas as informações disponiveis para acesso. Art. $6^{\circ}$, I - Dever dos órgãos de assegurar gestão transparente da informação, propiciando amplo acesso e divulgação. Art. $6^{\circ}$, II - Dever dos órgãos de assegurar proteção da informação, garantindose sua disponibilidade, autenticidade e integridade. Art. 12 - Gratuidade do serviço de busca e fornecimento da informação, salvo nas hipóteses de reproduçăo de documentos.

Art. $8^{\circ}, 83^{\circ}$, III - Sítios oficiais deverão possibilitar o acesso automatizado por sistemas externos em formatos abertos, estruturados e legíveis por máquina.

Art. $10,81^{\circ}$ - Possibilidade de qualquer interessado apresentar pedido de acesso a informaçōes, por qualquer meio legítimo, devendo o pedido conter a identificação do requerente, sem exigências mais que inviabilizem a

solicitação. Art. $10,82^{\circ}$ - Dever dos órgãos de viabilizar alternativa de encaminhamento de pedidos de acesso por meio de seus sítios oficiais na internet. Art. $10,3^{\circ}$ - Vedação de quaisquer exigências relativas aos motivos da solicitação de informações de interesse público.

Art. $8^{\circ}, 83^{\circ}$, II - Sítios oficiais deverão possibilitar a gravação de relatórios em diversos formatos eletrônicos, inclusive abertos e não proprietários tais como planilhas e texto, de modo a facilitar a

análise das informações. Art. $8^{\circ}, 83^{\circ}$, III - Sítios oficiais deverão possibilitar o acesso automatizado por sistemas externos em formatos abertos, estruturados e legiveis por máquina.

(Não há na LAI disposição sobre direito autoral (iij). Art. 24 - Possibilidade de classificaçăo da informação em poder dos órgãos públicos, observado o seu teor e em razão de sua imprescindibilidade à segurança da sociedade ou do Estado. Art. 28 - Classificação de informação em qualquer grau de sigilo deverá ser formalizada em decisão fundamentada, com indicação de prazo de sigilo e autoridade que a classificou. 
Fonte: Elaboração própria, com base em OpenGovData (2007) e Lei n.12.527 (2011).

Esta sinergia entre o direito de acesso à informação e o paradigma dos OGD restou selada no âmbito da APF com a edição do Decreto no 8.777/2016, que editou a Política de Dados Abertos do Poder Executivo Federal, institucionalizando um trabalho levado a cabo desde 2012. Além de organizar o planejamento e priorizar a abertura de determinados conjuntos de dados, a norma alterou redação do Decreto $n^{\circ} 7.724 / 2012$, que regulamenta a LAI na APF, incluindo no rol da transparência passiva também a possibilidade de pedido de abertura de bases de dados. Neste sentido, a LAI passou a compor objetivamente o arranjo normativo não só da política de acesso à informação, mas também da política de dados abertos no Governo Federal. Em virtude disso, interessa analisar o que a LAI entende por dado e informação públicos - e, portanto, passíveis de serem abertos.

\section{INFORMAÇÕES PÚBLICAS E INFORMAÇÕES RESTRITAS: DESAFIOS}

Segundo o princípio da completude, o paradigma dos OGD é aplicável a todos os dados públicos sob a guarda governamental e não apenas àqueles que as autoridades julgarem pertinentes, a menos que assim regulados por estatuto publicamente justificado. Por conseguinte, avaliar o grau de transparência possível, bem como as possibilidades de abertura de dados, implica delimitar objetiva e formalmente quais dados governamentais são passíveis de amplo acesso e quais não são.

Em consonância com a jurisprudência internacional, a LAI adota os princípios da divulgação máxima e da limitação das exceções. Deles decorrem que o acesso é a regra, e o sigilo, a exceção. São públicas, portanto, todas as informações coletadas ou armazenadas por todo tipo de organismo público (que desempenha funções públicas), devendo o direito de acesso abranger o maior tipo de informações (independentemente da forma como é arquivada: Em documentos, fita, gravação eletrônica, etc.) e alcançar o maior número de indivíduos possível. O acesso, por sua vez, pode ser restringido apenas em casos específicos previstos e limitados, por período de tempo determinado e devidamente justificado.

Conforme esclarece Cunha Filho (2017), a LAI e sua regulamentação na APF (Decreto no 7.724/2012) preveem hipóteses de restrições de acesso de duas naturezas: Substancial ou procedimental. Dentre as primeiras estão as relacionadas ao conteúdo da solicitação de informação, que pode ser objeto de classificação por requisitos de segurança, sigilo originário (informações pessoais) ou sigilo legal. Dentre as segundas, estão as relacionadas à forma do pedido. Incluem-se aí os pedidos considerados genéricos, desproporcionais ou que exijam trabalho adicional.

Não obstante a disposição legal, o nível de transparência adotado dependerá não só de como é estabelecido nas estruturas legais e institucionais "o que pode ser visto, o quanto e como pode ser visto e por quem (por quantos) pode ser visto”. Dependerá, outrossim, das estruturas políticas que o estabelecem (Gomes, 2017). Autores de diferentes matizes identificam o controle de informações como um recurso de poder fundamental no seio do Estado (e.g. Weber, 1982; Deutsch, 1971; Giddens, 2001; Braman, 2006). Por conseguinte,

Segredo, reserva, privacidade continuam valores ativos, mesmo em regimes estritamente liberais. Demais disso, é evidente que atores sociais fortes tendem a se eximir das obrigações e constrangimentos que os regimes de publicidade comportam, e há uma perene tensão política entre a publicidade que se deseja e a publicidade que se consegue (Gomes, 2017, p. 9).

Portanto, o conhecimento e a análise crítica das possibilidades de restrição de acesso são fundamentais para avaliar a amplitude do direito de acesso à informação (e de abertura) que pode ser efetivamente assegurado e reivindicado pela cidadania per se ou com a finalidade de exercer o entendimento esclarecido necessário à participação e à oposição nas poliarquias (Dahl, 2012). 


\subsection{Informações classificadas}

Como visto, no âmbito do direito de acesso à informação, as hipóteses de sigilo pretendem-se limitadas, encontrando-se no Brasil legal e claramente estabelecidas na LAI. Segundo a Controladoria-Geral da União (CGU), "o sigilo só pode ser justificado em casos em que o acesso à informação possa resultar em danos irreversíveis à sociedade ou ao Estado" (Manual da Lei de Acesso à Informação para Estados e Municípios, 2013 , p. 9). Para tanto, a lei federal lista exaustivamente um rol de informações que podem ser classificadas em diferentes graus de restrição de acesso (ultrassecreto, secreto e reservado), por meio de decisão administrativa da autoridade competente e por prazos específicos (Artigos 24 a 30). Cita-se, por exemplo, a defesa e a soberania nacionais ou a integridade do território nacional; a vida, a segurança ou a saúde da população; a estabilidade financeira, econômica ou monetária, entre outros (Artigo 23). Não enquadradas dentre as hipóteses listadas, não há possibilidade de classificação com base em outros fundamentos.

Embora especificadas as condições de classificação, não há garantia quanto à utilização dessa prerrogativa em casos que fogem ao interesse público. As resistências ao "olhar heterônomo" por parte dos agentes públicos (Gomes, 2017) e a cultura do segredo e do sigilo da burocracia (Weber, 1982) tensionam a fronteira entre a classificação e a transparência governamental. Cepik (2000, p. 150), ao tratar da compatibilidade entre segredo e o princípio da transparência e publicidade, observa que "não há antídotos definitivos contra o abuso do recurso ao segredo governamental". Assim, embora definida a necessidade de fundamentação e formalização da decisão de classificação e assegurada a possibilidade de pedido de reclassificação ou desclassificação, ainda restará espaço para a arbitrariedade - tendo em vista, sobretudo, a amplitude de interpretações passíveis de serem dadas às temáticas listadas (i.e. "segurança da população").

\subsection{Informações pessoais}

Além das exceções comportadas pelas hipóteses de classificação de restrição de acesso, não são públicos alguns dados e informações pessoais, entendidos como aqueles relacionados à pessoa natural identificada ou identificável (Art. $3^{\circ}$ ). Faz-se-o em respeito aos direitos à privacidade e à vida privada, cuja inviolabilidade é garantida pelo Art. 5\%, inciso X da Constituição Federal de 1988.

Contudo, não se trata de toda e qualquer informação pessoal, mas aquelas que se referem à intimidade, à vida privada, à honra e à imagem da pessoa (Art. 31). Nesses casos, a LAI estabelece o acesso restrito a agentes públicos legalmente autorizados, à pessoa a que elas se referirem (habeas data) ou a terceiros autorizados por consentimento expresso da pessoa - sendo este desnecessário em casos tais como de prevenção e diagnóstico médico e apuração de irregularidades, entre outros (Art. 31).

Não obstante a delimitação dos princípios e do tratamento a ser dado a informações pessoais, nem a LAI, nem o Decreto $\mathrm{n}^{\mathrm{0}} 7.724 / 2012$ definem de maneira clara quais seriam e quais não seriam informações pessoais sensíveis, passíveis de sigilo. Os escândalos de violação à privacidade de usuários de redes sociais e seu uso para manipulação eleitoral ${ }^{[\mathrm{iii}]}$ tornaram ainda mais urgente esta normatização, a qual somente veio a ser aprovada seis anos após a edição da LAI, em $2018^{[\mathrm{iv}]}$.

\subsection{Sigilo legal}

A LAI não revogou demais hipóteses legais de sigilo previamente reguladas por norma específica, as quais, em geral, estão vinculadas ao direito à privacidade (Acesso à Informação - Turma Piloto [Manual], 2017c). Isto é, consistem em informações que dizem respeito ao indivíduo na sua esfera privada, tais como as hipóteses de sigilo bancário, fiscal, de justiça, industrial, das sociedades anônimas, empresarial, de investigação 
de responsabilidade de servidor e de apuração de controle interno. Cabe citar ainda restrições de acesso decorrentes de direitos autorais.

Além das referências às hipóteses legais de sigilo, a Lei 12.527/2011 estabelece uma espécie de restrição especial de acesso de documentos preparatórios $\left(\right.$ Art. $\left.7^{\circ}, \$ 3^{\circ}\right)$. Por documento preparatório entende-se aquele que serve para fundamentar a tomada de decisão e (ou) o ato administrativo. Portanto, antes da edição do ato, há espaço para o órgão decidir pela disponibilização ou não de tais documentos, considerado o risco (ao processo, à finalidade da decisão e à sociedade) que a sua divulgação poderia causar. Concluída a decisão, contudo, os documentos deverão ter o seu acesso garantido à sociedade, a fim de que esta possa fazer o seu controle sobre os atos públicos (Acesso à Informação - Turma Piloto [Manual], 2017c).

\subsection{Informação inexistente}

Cunha Filho (2015) adiciona às hipóteses substanciais a resposta de "informação inexistente" (Art. 11,

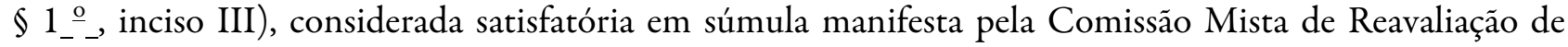
Informações (CMRI), última instância recursal da LAI. Nesses casos, cabe ao órgão comunicar que não possui a informação e indicar, se for de conhecimento, a organização que a detém.

Ao problematizar a relação entre direito de acesso à informação e direito à verdade no âmbito da justiça de transição, contudo, Cunha Filho (2015) adverte que a alegação de informação inexistente tem sido recorrentemente utilizada por órgãos da APF para negar acesso a informações referentes às violações de direitos humanos praticadas por agentes públicos durante o Regime Militar (1964-1985). Além desse emprego, o autor identificou a utilização de classificações de sigilo para justificar negativas de acesso, em total desrespeito à própria LAI, que veda expressamente esta conduta (Art. 21).

\subsection{Hipóteses processuais}

Para além das hipóteses substanciais previstas na LAI e em legislação específica, a regulamentação da lei na APF (Decreto n ${ }^{\circ} 7.724 / 2012$ ) adicionou uma segunda ordem de restrição de acesso à informação, de natureza procedimental, ao dispor que:

Art. 13. Não serão atendidos pedidos de acesso à informação:

I - Genéricos;

II - Desproporcionais ou desarrazoados; ou

III - Que exijam trabalhos adicionais de análise, interpretação ou consolidação de dados e informações, ou serviço de produção ou tratamento de dados que não seja de competência do órgão ou entidade.

Parágrafo único. Na hipótese do inciso III do caput, o órgão ou entidade deverá, caso tenha conhecimento, indicar o local onde se encontram as informações a partir das quais o requerente poderá realizar a interpretação, consolidação ou tratamento de dados. (Decreto n. 7.724, 2012).

Essas hipóteses decorrem da compreensão de que o atendimento completo desses pedidos de informação pode colidir com outros princípios da Administração Pública e até mesmo com o direito de outros cidadãos, especialmente quando se trata de pedidos que exigiriam significativa alocação de recursos para seu atendimento (Acesso à Informação - Turma Piloto [Manual], 2017c; Cunha Filho, 2017).

Embora compreensível, preocupa, neste sentido, o espaço aberto para a caracterização da desproporcionalidade e de trabalho adicional, tendo em vista o ciclo de vida para a produção e publicação de um dado em formato aberto. Em virtude das especificações técnicas e legais que diferem das práticas institucionalizadas pelas iniciativas pretéritas de governo digital (Fountain, 2014), o processo de abertura de dados envolve necessariamente não só a publicação de dados na internet, mas também uma reorientação na gestão da informação (Weinstein \& Goldstein, 2012), isto é, a disponibilização de dados em formato aberto 
envolve mudanças nas práticas de armazenamento, organização, classificação e publicação de informações, e isso necessariamente implicará em esforços adicionais ${ }^{[\mathrm{v}]}$. Além do trabalho envolvido na estruturação e formatação dos arquivos, há conjuntos de dados que também exigem previamente a limpeza ou a aplicação de tarja sobre o conteúdo sigiloso ou classificado e (ou) a sua anonimização, caso contenha informações pessoais de acesso restrito.

Com a finalidade de delimitar a margem de discricionariedade aberta pela norma infralegal à aplicação dessas hipóteses de restrição de acesso, a CGU, na qualidade de responsável pelo monitoramento da LAI na APF, definiu cada uma, indicando, ainda, as medidas a serem adotadas pelos órgãos quando de sua utilização (CGU, 2015). O Quadro 2 sintetiza os casos de interesse.

$$
\begin{gathered}
\text { Quadro } 2 \text { - Definições de pedido genérico, desproporcional, } \\
\text { desarrazoado e pedido que exija trabalho adicional }
\end{gathered}
$$

\begin{tabular}{|c|c|c|}
\hline Caso & Definição & $\begin{array}{l}\text { Tratamento a ser dispensado } \\
\text { pelo órgão }\end{array}$ \\
\hline Desproporcionalidade & $\begin{array}{l}\text { Quando a informação existe e } \\
\text { não é sigilosa, mas o } \\
\text { atendimento do pedido pode } \\
\text { demandar o trabalho de toda } \\
\text { uma unidade, por um periodo } \\
\text { considerável de tempo, } \\
\text { comprometendo suas } \\
\text { atividades rotineiras e, assim, } \\
\text { acarretando prejuizo às suas } \\
\text { atribuiçốes ou mesmo aos } \\
\text { direitos de outros cidadãos. }\end{array}$ & $\begin{array}{l}\text { Exigência de clara e concreta } \\
\text { apresentação do nexo entre o } \\
\text { atendimento do pedido e os } \\
\text { impactos negativos (razões de } \\
\text { fato). Cabe indicar que o } \\
\text { atendimento demandaria horas } \\
\text { de trabalho e servidores tais } \\
\text { que inviabilizaria a rotina da } \\
\text { unidade responsável. }\end{array}$ \\
\hline $\begin{array}{l}\text { Exigência de } \\
\text { trabalhos adicionais }\end{array}$ & $\begin{array}{l}\text { Quando a informação ou o } \\
\text { dado solicitado não estão no } \\
\text { formato especificado pelo } \\
\text { requerente, precisando } \\
\text { receber tratamento (análise, } \\
\text { interpretação ou } \\
\text { consolidação) que ou não } \\
\text { estão dentre as competências } \\
\text { da instituição, ou exigem } \\
\text { esforços que o órgão não teria } \\
\text { condições de oferecer, em } \\
\text { função de dificuldades } \\
\text { técnicas ou carência de } \\
\text { recursos humanos. }\end{array}$ & $\begin{array}{l}\text { Exigência de clara e concreta } \\
\text { apresentação do nexo entre o } \\
\text { atendimento do pedido e os } \\
\text { impactos negativos (razões de } \\
\text { fato). Cabe indicar que o } \\
\text { trabalho exigido para } \\
\text { atendimento do pedido ou não } \\
\text { é da competência do órgão, ou } \\
\text { demandaria horas de trabalho } \\
\text { e servidores tais que } \\
\text { inviabilizaria a rotina da } \\
\text { unidade responsável. Caso de } \\
\text { conhecimento, cabe também } \\
\text { indicar o local onde se } \\
\text { encontram as informações } \\
\text { demandadas, para que o } \\
\text { próprio cidadão possa realizar } \\
\text { a agregação desejada. }\end{array}$ \\
\hline
\end{tabular}

Fonte dos dados brutos: Aplicação da Lei de Acesso à Informação em recursos da CGU, 2015; Acesso à Informação - Turma Piloto [Manual], 2017c.

Ademais, ciente da possibilidade de aplicação arbitrária das hipóteses processuais, o Decreto $\mathrm{n}^{\circ}$ 8.777/2016, que instituiu a Política de Dados Abertos no Poder Executivo Federal, reforça a orientação da CGU quanto à necessidade de apresentar justificativas baseadas em razões de fato quando do emprego da hipótese de trabalho adicional, tal como a quantificação dos custos hora/servidor para a abertura dos dados demandados via SIC. Ademais, requer apresentação de análise de viabilidade da inclusão desses dados no planejamento de abertura de dados do órgão, o chamado Plano de Dados Abertos (PDA).

Destarte, a fim de verificar empiricamente os desafios à institucionalização do paradigam dos OGD na gestão pública brasilera, apresenta-se o estudo de caso a seguir. 


\section{Procedimentos metodológicos do estudo de caso}

Com vistas a analisar o tratamento efetivamente dispensado a pedidos de abertura de dados e, em específico, a aplicação das hipóteses de restrição de acesso listadas acima, realizou-se um estudo de caso do Governo Federal brasileiro, tomando-se como unidades de análise os pedidos de acesso à informação realizados aos órgãos públicos federais por meio do Sistema Eletrônico do Serviço de Informações ao Cidadão (e-SIC), as respostas a eles conferidas em primeira instância pelos órgãos, bem como os recursos julgados em última instância pela Comissão Mista de Reavaliação de Informações. Os dados foram obtidos diretamente do eSIC, cuja base passou a ser disponibilizada em formato aberto a partir de 11 de julho de 2015, data de início, portanto, da presente análise (Busca de Pedidos e Respostas. Brasília: Controladoria-Geral da União, 2017a).

Para fins de análise, primeiramente, o conteúdo foi categorizado segundo termos preestabelecidos, que traduzem características fundamentais dos OGD, conforme depreendido da literatura especializada. Do mais específico ao mais genérico, são eles: "Dado aberto/open data"; "formato aberto"; "padrão aberto"; "formato não proprietário"; "padrão não proprietário"; "em csv/ em .csv/ formato csv/ formato .csv" (e variações: $\mathrm{Xml}$, txt, png, odt, json, rdf); "creative commons"; "formato estruturado"; "dado bruto"; "desagregado"; "editável"; "planilha" e respectivas flexões de gênero e número, quando couberam. Nem todos os termos foram localizados nas unidades analisadas.

Das solicitações ou respostas contendo um ou mais termos de interesse, selecionaram-se apenas as unidades que se referiam especificamente a formatos abertos, bases de dados brutos ou algum tipo especificado de agregação (ou desagregação) relacionado ao paradigma dos dados abertos. Essas unidades constituíram base de dados especificamente contruída para a análise. Adicionalmente, com a finalidade de comparar os tratamentos dispensados e verificar a existência (ou não) de mudança de padrão de resposta após a publicação do Decreto $\mathrm{n}^{\circ}$ 8.777/2016, que instituiu a Política de Dados Abertos, foram estabelecidos dois recortes temporais, denominados "período 1" (11 de julho de 2015 a 11 de maio de 2016) e "período 2" (12 de maio de 2016 a 31 de julho de 2017).

Finalmente, o número e a frequência de aplicação das hipóteses substanciais e processuais de restrição de acesso à informação foram apurados. A partir desses resultados, buscou-se identificar a existência (ou não) de padrões de justificativas utilizados pelos órgãos e entidades públicos federais para negar o acesso às informações solicitadas. Essa última etapa foi operada somente sobre os pedidos protocolados após a edição da Política de Dados Abertos, isto é, o período 2, dado que esta buscou delimitar de maneira mais objetiva o tratamento a ser dado em caso de restrição de acesso por hipótese processual, como visto.

Os mesmos procedimentos acima foram realizados com as decisões da CMRI. A seguir, apresentam-se os resultados para os oito conjuntos de termos com maior ocorrência.

\section{Pedidos de abertura de dados: ocorrênCias E Tratamentos EM PRimeira e Última INSTÂNCIAS}

Entre 11 de julho de 2015 e 31 de julho de 2017, foram protocoladas 172.993 solicitações de acesso à informação a órgãos e entidades públicas federais, dos quais $65,3 \%$ foram atendidos e 13,06\% foram negados total ou parcialmente (Figura 1). Destes, $10 \%$ o foram por serem considerados genéricos; $8 \%$, por exigirem trabalho adicional de análise, interpretação ou consolidação e, finalmente, $5 \%$, por conter demanda desproporcional ou desarrazoada. Cerca de um quarto das negativas de acesso, portanto, fizeram uso de hipóteses processuais. A Figura 1 ilustra esses resultados. 

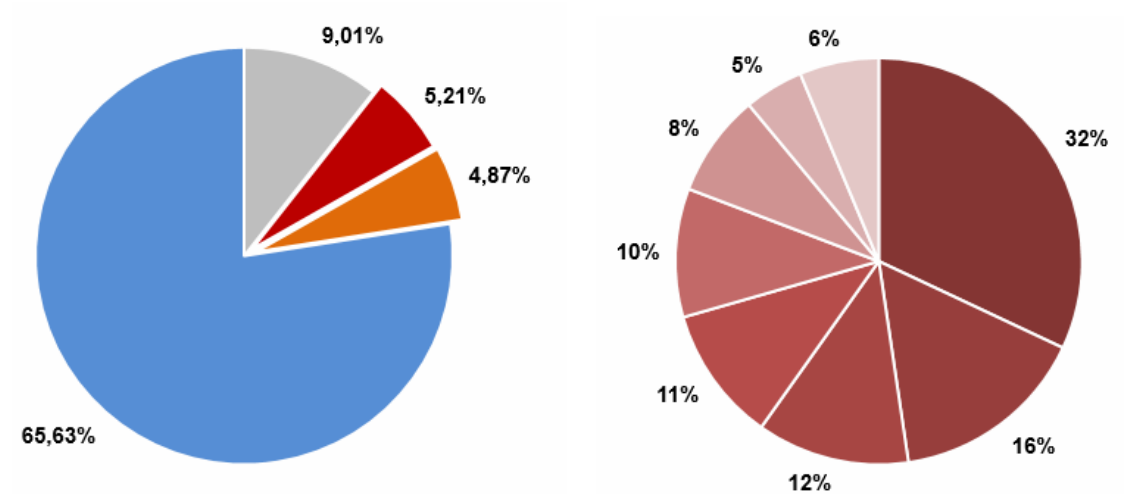

$$
\begin{aligned}
& \text { - Sem registro de tratamento } \\
& \text { - Acesso negado } \\
& \text { - Acesso parcialmente concedido } \\
& \text { - Acesso concedido }
\end{aligned}
$$

$$
\begin{aligned}
& \text { - Informação inexistente } \\
& \text { - Dados pessoais } \\
& \text { - Informação classificada } \\
& \text { - Sigilo legal } \\
& \text { - Pedido genérico } \\
& \text { - Pedido exige tratamento adicional de dados } \\
& \text { - Pedido é desproporcional ou desarrazoado } \\
& \text { - Pedido é incompreensível }
\end{aligned}
$$

FIGURA 1

- Tratamento dispensado a pedidos de acesso à informação protocolados

via SIC federal à esquerda e justificativas para negação ou concessão parcial de informações solicitadas à direita - julho2015 a julho2017

Fonte dos dados brutos: Busca de Pedidos e Respostas. Brasília: Controladoria-Geral da União, 2017a.

Ainda que, considerando o universo de pedidos protocolados, o número de ocorrências dos termos relacionados ao paradigma dos dados abertos seja ínfimo - foram identificadas 699 ocorrências, seja em perguntas ou respostas -, a análise comparativa entre os recortes temporais adotados revela um crescimento no emprego desses termos entre o período 1 e o período 2: De 217 para 482 - um aumento de mais de $222 \%$, o qual evidencia a difusão do paradigma dos dados abertos entre usuários potenciais. As ocorrências dos conjuntos de termos de interesse podem ser visualizadas na Figura 2.

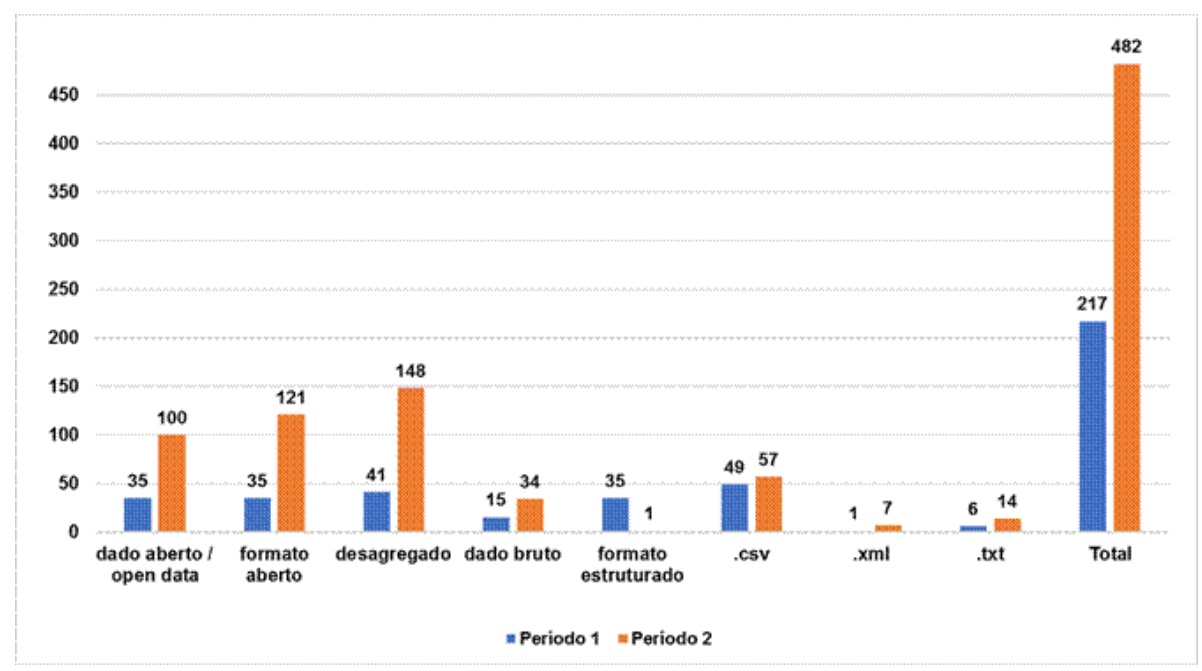

FIGURA 2

- Ocorrência de termos relacionados ao paradigma dos dados abertos nos pedidos e nas respostas a solicitações de acesso à informação protocoladas via SIC federal - julho2015 a julho2017 Fonte dos dados brutos: Busca de Pedidos e Respostas. Brasília: Controladoria-Geral da União, 2017a. 
No que se refere às categorias de tratamento conferido pelo órgão requerido em cada um desses casos, as taxas médias mantiveram-se de um período para o outro: Cerca de $68 \%$ teve acesso concedido; $8,5 \%$, parcialmente concedido e $8 \%$, negado. Alteraram-se, contudo, os motivos mais empregados para negar acesso: Enquanto no primeiro período as justificativas mais utilizadas foram de cunho processual $(63,16 \%)$, no segundo período, distribuem-se entre processual (47,06\%) e substancial (55,88\%). Em ambos, entretanto, cerca de $20 \%$ dos pedidos negados o foram por exigência de trabalho adicional. A Figura 3 ilustra essa distribuição para os conjuntos de termos com maior ocorrência de negativas, em que se percebe a predominância dessa justificativa dentre as demais.

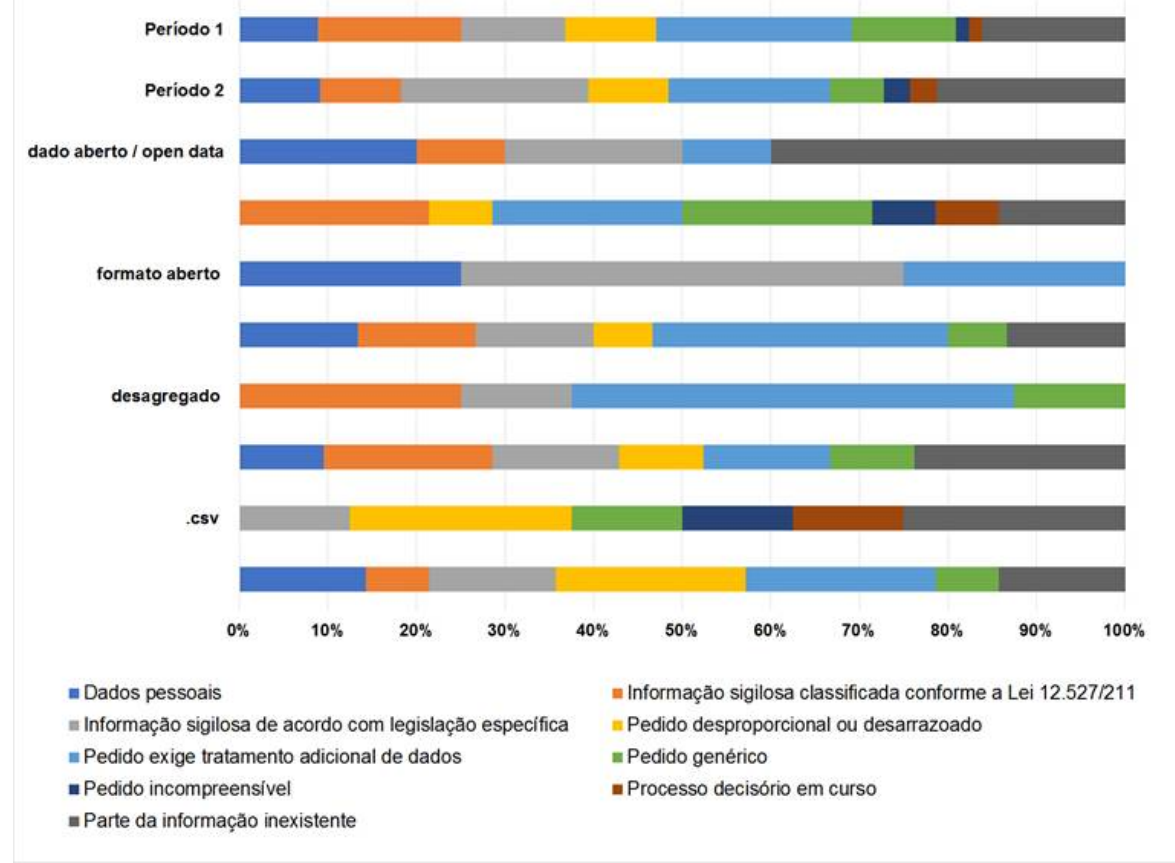

FIGURA 3

- Pedidos de abertura de dados negados total ou parcialmente por conjunto de termos e tipo de justificativa - julho2015 a julho2017

Fonte dos dados brutos: Busca de Pedidos e Respostas. Brasília: Controladoria-Geral da União, 2017a.

Considerando os pedidos protocolados após a edição da Política de Dados Abertos, em maio de 2016, a análise das justificativas empregadas evidencia que é rara a manifestação objetiva não só das razões de direito, mas também das razões de fato para negar (total ou parcialmente) o acesso aos dados no formato solicitado, conforme orienta a CGU (Aplicação da Lei de Acesso à Informação em recursos da CGU, 2015). Por exemplo, em negativas conferidas pela Agência Nacional de Saúde Suplementar, argumenta-se que:

[...] Realizar esta atividade neste momento não seria razoável, visto que seria necessário destacar um Servidor Público para realizar tal tarefa, por um tempo mínimo de uma semana (Identificador Único do Pedido [ID] 420258).

O Sistema [...] tem um cadastro de mais de 360 milhões de registros e volume de dados de mais de 100GB. Sua exportação e anonimização envolveria um processo não trivial de execução e oneroso do ponto de vista do processamento para consolidação em tabelas (ID 487205).

Salvo exceções, é igualmente rara a ponderação quanto à viabilidade de incluir a base de dados solicitada no Plano de Dados Abertos do órgão, como exige o Decreto no 8.777/2016. Dentre as exceções, citamos, por exemplo, respostas conferidas pelo Instituto Nacional de Propriedade Industrial (ID 481812 e 483658), bem como pela Coordenação de Aperfeiçoamento de Pessoal de Nível Superior (ID 515774). Embora os órgãos não especifiquem os custos para atenderem aos pedidos, esclarecem que a abertura dos dados demandados está prevista em seus PDAs. 
$\mathrm{Na}$ análise, chama a atenção o emprego da hipótese infralegal de trabalho adicional, inclusive para negar a concessão de informações já previamente publicadas na internet, mas em formato apenas de consulta (não passível, portanto, de extração e reutilização). Assim, registra-se o pedido ID 400549, encaminhado ao Ministério da Educação, ao que o órgão alega não ser possível atender, pois não estaria previsto dentre os direitos regulados pela LAI (Art. $7^{\circ}$ ) o de solicitar a produção de bases de dados customizadas de acordo com o interesse do cidadão, em flagrante deturpação do dispositivo. Posicionamento equivalente conferiu o órgão a outros pedidos (i.e. ID 406123, 395777, 438589, etc.). Em nenhum dos casos foram apresentados objetivamente os custos que seriam necessários para atender ao pedido, nem a análise da viabilidade de incluir a base no PDA do órgão, nem mesmo foi indicado o local ou os meios alternativos para que o cidadão pudesse encontrar as informações por conta própria e, assim, imprimir a interpretação ou o tratamento desejado.

Para além da hipótese infralegal de trabalho adicional, registra-se o uso frequente de justificativas de sigilo legal. Por exemplo, cita-se a reiterada menção ao sigilo bancário para negar acesso a dados sobre empreendimentos da faixa 2 e 3 do Programa Minha Casa Minha Vida (i.e. ID 473216, 477604, 479536, etc.), sob a justificativa de que "o detalhamento das informações para estas faixas permite a identificação das empresas que contraíram financiamento de caráter privado para a realização dos mesmos” (ID 521436). Este posicionamente não só afronta o dispositivo da LAI que assegura inclusive o direito de obter informação produzida por entidade privada decorrente de qualquer vínculo com o Poder Público (Quadro I), como também cerceia a possibilidade de controle social sobre a parcela de recurso público que compóe o Programa.

A inexistência, à época, de norma específica sobre tratamento de dados pessoais também conduziu à decisão arbitrária de negativa de acesso a dados pessoais não considerados sensíveis, tais como os relativos a nascimentos, casamentos, divórcios e óbitos, constantes no Sistema Nacional de Informações de Registro Civil - SIRC (Pedido ID 418118), cuja abertura foi inclusive elencada como prioritária na Política de Dados Abertos.

Diante da negativa de acesso, portanto, a previsão de recurso apresenta-se como uma salvaguarda ao direito à informação - cobrando, contudo, maiores custos transacionais. No caso da APF, as instâncias recursais compreendem, nesta ordem, a autoridade hierarquicamente superior ao gestor da LAI no órgão, a autoridade máxima do órgão, a CGU e, em última instância, a CMRI, órgão colegiado composto por dez ministérios e presidido pela Casa Civil. A previsão de recurso em quatro instâncias não significa, porém, direito à informação assegurado. Segundo observa Cunha Filho (2017), é baixa a probabilidade de que o dirigente máximo de um órgão, cargo em geral de livre nomeação e exoneração e ocupado por pessoas alinhadas política e ideologicamente, reverta uma decisão e decida conceder acesso a informações que sejam contrárias ao interesse do governo, por exemplo. O mesmo vale para decisões do Corregedor-Geral. Quanto à CMRI, sua composição ministerial, sem representação externa (Parlamento, por exemplo), mantém o controle do Executivo sobre o processo, o que lhe priva de autonomia e independência em relação ao governo (Cunha Filho, 2017).

Destarte, é muito baixo o percentual de recursos concedidos (parcial ou totalmente) pelo órgão colegiado desde sua instalação. Dos 2.315 recursos julgados entre novembro de 2012 e março de 2017 (Recursos julgados pela CMRI. Decisóes, 2017b), verifica-se que apenas 13 foram providos e 5 foram parcialmente providos, todos contra órgãos diversos aos que compõem a CMRI, à exceção do Ministério da Fazenda, com 2 recursos deferidos.

No que concerne especificamente ao tema desta pesquisa, dos 377 recursos julgados nas reuniões da CMRI no período 1 (9,57\% dos pedidos negados em primeira instância), identificaram-se apenas sete tratando de solicitações sobre informações ou bases de dados em formatos específicos ou com algum tipo especificado de agregação ou desagregação ${ }^{[v i]}$. Conquanto, todos os recursos foram indeferidos. Em quase sua totalidade, a reiterada negativa de acesso assentou-se na hipótese processual de trabalho adicional. Em poucos casos o órgão demandado discorreu objetivamente sobre a quantidade de horas e (ou) de recursos necessários para o atendimento do pedido. Limitavam-se, em geral, a alegar impacto na rotina de funcionamento do órgão, sem 
demonstrar nexo causal. Poucos, ainda, indicaram o local ou meios alternativos para que o cidadão acessasse os dados de maneira autônoma.

Vale mencionar decisões que, apesar de indeferirem o recurso, orientam os órgãos a trabalharem no sentido de organizar e classificar seus dados para disponibilizá-los futuramente via transparência ativa ou passiva, antes mesmo da exigência estabelecida pelo Decreto no 8.777/2016. Destacam-se, nesse sentido, as decisões acerca dos dados da arrecadação tributária mensal por parte do MF (Decisão n 199/2015) e da Plataforma Lattes, por parte do Conselho Nacional de Desenvolvimento Científico e Tecnológico (Decisão $n^{\circ}$ 403/2015).

No período 2, por sua vez, dos 896 recursos julgados pela CMRI (17,65\% dos pedidos negados em primeira instância), identificaram-se 18 abordando a temática de interesse ${ }^{\text {[vii] }}$. Dentre eles, 15 mantiveram a denegatória de acesso, 2 foram deferidos e 1 parcialmente deferido. Em apenas um caso é que, por requisição da CGU (terceira instância), o órgão passou a quantificar o esforço que seria requerido para disponibilizar os dados na estrutura demandada pelo cidadão, diante de negativa de acesso por trabalho adicional (Decisão $\left.\mathrm{n}^{\circ} 006 / 2017\right)$.

Ainda neste sentido, vale mencionar decisão sobre recurso de pedido realizado à Previdência Social (Decisão $n^{\circ}$ 037/2017). No processo, a CGU questiona o órgão demandado quanto à possibilidade de disponibilizar a base de dados bruta para livre manipulação, ao que o órgão contesta envolver grande esforço para compilar e validar dados de diferentes sistemas. A CGU acata o posicionamento do órgão e o recurso é indeferido. Contudo, destacamos a manifestação do solicitante, em que denuncia o emprego de dispositivos infralegais do Decreto n ${ }^{\circ} 7.724 / 2012$ :

O recorrente [...] argumenta que as informações são existentes e não estão protegidas por sigilo. Questiona como o governo elaborou a proposta de reforma da previdência se desconhece os dados. Além disso, reafirma que a negativa é ilegal, pois não tem amparo em lei, mas em simples decreto (Decisão ${ }^{\circ}$ 037/2017).

Aqui, encontra-se evidência à preocupação manifesta por Yu e Robinson (2012) quando refletem criticamente sobre a relação entre transparência, dados abertos e prestação de contas. Ao negar acesso a dados potencialmente polêmicos do ponto de vista político, cerceia-se o efetivo exercício do direito de acesso à informação pública, necessário ao entendimento esclarecido (Dahl, 2012) e, em última instância, ao controle social de uma agenda de reforma com significativo impacto social e econômico.

Por fim, cabe questionar o posicionamento da Comissão na Decisão n 633/2016. Incialmente negada a solicitação por hipótese de sigilo legal, em segunda instância o órgão passa a alegar exigência de trabalho. Recursalmente, o demandante aponta a falta de caracterização objetiva do esforço requerido, em descumprimento não só ao Decreto n 7.724/2012, mas também à Política de Dados Abertos. A CMRI contesta:

Quanto ao argumento do recorrente baseado no art. $6^{\circ}$ do Decreto no $8.777 / 16$, trata-se de solicitação diversa, com objetivo de abertura de bases de dados da Administração Pública Federal, que deverá correr em rito próprio (grifo nosso).

Ou seja, só caberia invocar a Política de Dados Abertos quando de pedido específico de abertura de base de dados e não em pedido genérico de acesso à informação. Esta distinção restringe o exercício do direito, impondo ao cidadão o ônus de conhecer ritos administrativos e definições técnicas que são próprias da burocracia (Weber, 1982). A própria LAI é taxativa ao dispor que é dever do Estado garantir e franquear o direito de acesso à informação, mediante procedimentos objetivos, claros e de fácil compreensão.

Em síntese, a análise evidencia a ampla utilização da hipótese infralegal de trabalho adicional para negar acesso a informações ou dados em formato, estrutura ou agregação (ou desagregação) específicos, seja em primeira instância, seja ao longo das instâncias recursais. Isto é, quando negativas baseadas nas hipóteses substantivas são contestadas pelo requerente alegando que os bancos de dados poderiam ser anonimizados ou tarjados a fim de franquear acesso ao conteúdo público, por exemplo, os órgãos passam a contestar 
trabalho adicional, e a denegatória é mantida. Além desse padrão, identificou-se também a utilização dessa hipótese quando da necessidade de realizar apurações especiais de informações em diferentes sistemas e junto a prestadores de serviços de informática (majoritariamente empresas terceirizadas, como apontam Cepik e Canabarro, 2014), o que resultaria em custos não previstos pelo órgão.

\section{Conclusão}

A LAI é pioneira no mundo a incorporar o paradigma dos dados abertos no escopo da regulamentação do direito de acesso à informação, em um movimento sinérgico catalisado pela participação brasileira na Open Government Partnership. Inicialmente inseridos no âmbito da transparência ativa da Lei, pedidos de abertura de dados passaram a poder ser demandados ao Governo Federal também por meio dos procedimentos da transparência passiva, inovação inserida a partir da edição da Política de Dados Abertos (Decreto $n^{\circ}$ 8.777/2016). Destarte, à avaliação das possibilidades e dos desafios à adoção dos OGD no Brasil, interessa analisar a institucionalidade vigente da transparência, em especial a definição e a aplicação do que é público e, portanto, passível de abertura.

A Lei de Acesso à Informação adotou o acesso como a regra. Nesse contexto, no que compete ao abrigo dos princípios dos dados abertos governamentais pela norma, para além do dispositivo do Artigo $8^{\circ}$ da Lei, que explicitamente menciona a gravação de dados em formato aberto, outros são passíveis de serem identificados. Para além da definição do padrão técnico dos dados e informações a serem prestados, reconhecem-se na LAI características fundamentais dos OGD, tais como a de serem acessíveis (amplo acesso e disponibilidade) e não discriminatórios (a qualquer interessado).

Por sua vez, a LAI determinou o sigilo como exceção. Para tanto, especificou os tipos, os graus e os prazos máximos de sigilo de informações, conforme seu conteúdo. Contudo, afora essas restrições de cunho substancial, hipóteses processuais foram adicionadas por meio da regulamentação da Lei no Governo Federal - Decreto $n^{\circ} 7.724 / 2012$. Dentre elas, chama atenção a inclusão pela norma infralegal de dispositivo que ampara o não atendimento de pedidos "que exijam trabalhos adicionais de análise, interpretação ou consolidação de dados”. Isso porque, em virtude das especificações técnicas e legais que diferem das institucionalizadas (Fountain, 2014), a abertura de dados necessariamente envolverá esforços e recursos para sua organização, classificação, formatação e disponibilização por meio da transparência passiva ou ativa (Weinstein \& Goldstein, 2012).

Com efeito, ao analisar empiricamente o tratamento dispensado em primeira e última instância a solicitações de abertura de dados protocoladas junto ao Sistema Eletrônico do Serviço de Informações ao Cidadão (e-SIC), em períodos anteriores e posteriores à edição da Política de Dados Abertos, verificou-se que a hipótese de "trabalho adicional" foi a mais empregada para negar acesso a dados em algum formato, estrutura ou agregação (ou desagregação) específicos. Salvo exceções, emprego desse dispositivo processual foi desacompanhado de justificativas que apresentassem o nexo causal entre o atendimento da solicitação e possíveis impactos negativos na rotina do órgão, conforme legalmente exigido e orientado pela CGU.

A possibilidade de recurso em quatro instâncias tampouco assegura reconsideração de decisão que contrarie negativa inicialmente adotada pelo órgão. Com efeito, das 25 decisões adotadas pela CMRI nos períodos analisados, apenas 2 apontaram pelo deferimento do recurso. A composição da CMRI e a inexistência de controle externo sobre suas decisões acinzentam ainda mais esse cenário (Cunha Filho, 2017).

Portanto, a despeito dos avanços registrados com a incorporação de princípios dos dados abertos governamentais na Lei de Acesso à Informação, a adoção do paradigma no Brasil é desafiada pela amplitudade das hipóteses de negativas de acesso, de ordem substancial e processual. Em específico, requerem atenção a interpretação das hipóteses de sigilo, aberta à discricionariedade; a ausência de tratamento legal às informações pessoais, que ampara restrição de acesso a dados não sensíveis; as hipóteses processuais adicionais 
reguladas infralegamente, que sustentam o não atendimento por ocasião da burocracia, e o controle governamental sobre os processos recursais, que dificulta a reversão de denegatória inicial.

Nessas condições, considerando o peso dos "poderes invisíveis" (Bobbio, 1987) e da "cultura do segredo" (Weber, 1982), somado à assimetria informacional que pende contratariamente aos cidadãos, restam espaços para negativas deliberadas de acesso à informação, legalmente abrigados sob a institucionalidade vigente. Conforme pontua Gomes (2017, p. 17), "embora tenhamos caminhado aceleradamente para a institucionalização e a legalização do acesso à informação, a transparência consistentemente esbarra em cotas iníquas de poder discricionário ainda em mãos dos [...] guardas dos portões, do Estado". Esse obstáculo não é exclusivo ao Governo Federal brasileiro. Ao comparar os movimentos de direito à informação e de OGD, Janssen (2012) observa que:

Ambos [...] encontraram, ao longo de seu desenvolvimento, obstáculos comparáveis dentro do governo, como órgãos públicos mantendo sua antiga cultura de sigilo e usando argumentos de privacidade, segurança nacional, segredo comercial, etc., para limitar o acesso a dados e informações (p. 4, tradução nossa).

Evidentemente, não se trata de afirmar que as hipóteses de restrição de acesso não têm sido adequadamente aplicadas pelo Governo Federal. Avaliar o mérito das decisões foge ao escopo desta pesquisa. Busca-se, sim, chamar a atenção para esse espaço cinzento criado, sobretudo, por hipóteses processuais criadas por regramento infralegal que extrapola o deliberado e aprovado pelo Congresso Nacional por meio da Lei ${ }^{\circ}$ 12.527/2011. Análise da persistência desse tipo de tratamento dedicado ao paradigma merece avaliação continuada não só no âmbito da Administração Pública Federal, mas também nos demais níveis e Poderes, tendo em vista que muitos reproduzem para si a regulamentação da LAI adotada na APF (Morassutti, 2017).

Diante desse quadro, cabe esperar que a crescente disponibilização de OGD por meio de transparência ativa, seja por meio do Portal Brasileiro de Dados Abertos, seja por meio de congêneres estaduais ou municipais, consiga demonstrar que, ao contrário do alegado ônus adicional, a reorientação da produção e da gestão da informação por parte das burocracias contribui no sentido contrário, isto é, na economia de recursos - seja por meio da redução de pedidos via e-SIC, seja por meio da organização mais eficiente e menos redundante das informações da própria Administração Pública (Batista, Silva, \& Miranda, 2013; Weinstein \& Goldstein, 2012). Enquanto isso, reitera-se a importância do papel do controle social sobre a implementação da LAI de facto, e não apenas de jure. Este trabalho buscou contribuir nesse sentido, ao evidenciar, por meio da análise empírica e não somente normativa, os renitentes desafios que se interpõem à garantia do direito de acesso à informação na era digital.

\section{REFERÊNCIAS}

Access Info. (2011). Beyond Access: Open Government Data and the Right to Reuse. Retrieved from https://www.a ccess-info.org/uncategorized/11094.

Artigo 19. (2009). Princípios para uma legislação sobre acesso à informação pública . Recuperado de http://artigo19.o $\mathrm{rg} /$ infoedireitoseu/? $\mathrm{p}=81$.

Batista, A. H., Silva, N. B., Miranda, C. M. C. (2013, abril). Infraestrutura nacional de dados abertos. Anais do Congresso CONSAD de Gestão Pública, Brasília, DF, Brasil, 6.

Braman, S. (2006). Change of State. Cambridge, MA: The MIT Press.

Manual da Lei de Acesso à Informação para Estados e Municipios. (2013). Brasília: Controladoria-Geral da União.

Aplicação da Lei de Acesso à Informação em recursos da CGU. (2015). Brasília: Controladoria-Geral da União.

Busca de Pedidos e Respostas. (2017). Brasília: Controladoria-Geral da União. Recuperado de http://www.acessoainf ormacao.gov.br/assuntos/busca-de-pedidos-e-respostas.

Recursos julgados pela CMRI. Decisóes. (2017). Brasília: Controladoria-Geral da União. Recuperado de http://www.a cessoainformacao.gov.br/assuntos/recursos/recursos-julgados-a-cmri/decisoes/. 
Ana Júlia Possamai, et al. Transparência e Dados Abertos Governamentais: Possibilidades e Desafio...

Acesso à Informação - Turma Piloto [Manual]. (2017). Brasília: Escola Nacional de Administração Pública.

Bobbio, N. (1987). O futuro da Democracia: uma defesa das regras do jogo. Rio de Janeiro: Paz e Terra.

Cepik, M., Canabarro, D. (2014). Governança de TI: Transformando a Administração Pública no Brasil. Porto Alegre: WS Editor.

Cepik, M. Direito à informação: situação legal e desafios. (2000). Informática pública, Belo Horizonte, 2(2), 43-56.

Cunha Filho, M. (2015). O Desencontro entre Direito à Informação e Direito à Verdade: Análise das Práticas da Controladoria-Geral da União. Direito, Estado e Sociedade, 47, 91-107.

Cunha Filho, M. (2017). Right to Information in Brazil: tensions between transparency and control of information. Law and Politics in Africa, Asia and Latin America, 50 (4), 412-434.

Dahl. R. A. (2012). A democracia e seus críticos. São Paulo: Martins Fontes.

Decreto $n^{\circ} 7.724$, de 16 de maio de 2012. Regulamenta a Lei no 12.527... Diário Oficial da União, Brasília, DF.

Decreto $n^{\circ} 8.777$, de 11 de maio de 2016. Institui a Política de Dados Abertos do Poder Executivo federal. Diário Oficial da União, Brasília, DF.

Deutsch, K. W. (1971). Os nervos do governo. Rio de Janeiro: Bloch.

Diniz, V., Guimarães, C. B. S. (2013, abril). Os desafios para um país digitalmente aberto. Anais do Congresso CONSAD de Gestão Pública, Brasília, DF, Brasil, 6.

Fountain, J. E. (2014). On the Effects of e-Government on Political Institutions. In D. Kleinman and K. Moore (Ed.), Handbook of Science, Technology and Society (471-487). Nova York: Routledge.

Giddens, A. (2001). O Estado-nação e a violência. São Paulo: Edusp.

Gigler, S., Custer, S., Rahemtulla, H. (2011). Realizing the vision of open government data. Retrieved from http://www.scribd.com/doc/75642397/Realizing-the-Vision-of-Open-Government-Data-Long-Versio n-Opportunities-Challenges-and-Pitfalls.

Janssen, K. (2012). Open Government Data and the Right to Information: Opportunities and Obstacles. The Journal OfCommunity Informatics, 8 (2). Retrieved from http://ci-journal.org/index.php/ciej/article/view/952.

Gomes, W. S. (2017). Transparência Pública. In: W. S. Gomes. (Org.), Programa de Treinamento Profissional em Democracia Digital e Governança Democrática. Salvador: INCT.DD.

Laporte, T., Demchak, C., Friis, C. (2000). Webbing governance: national differences in constructing the face of public organizations. In D. Garsons. (Ed.), Handbook of public information systems (179-196). Nova York: Marcel Dekker Publishers.

Lei n $n^{\circ}$ 12.527, de 18 de novembro de 2011. Regula o acesso a informações... Diário Oficial da União, Brasília, DF.

Morassutti, B. S. (2017). Regulação do Acesso à Informação Pública na Federação Brasileira: compilação de Normas Federais e Estaduais. Retrieved from https://ssrn.com/abstract=2966910.

Núcleo de Informação e Coordenação do Ponto Br. (2017). Pesquisa TIC Governo Eletrônico 2017. São Paulo: Centro Regional para o Desenvolvimento da Sociedade da Informação.

OpenGovData. (2007). The annotated 8 principles of open government data. Retrieved from http://opengovdata.org/.

Peixoto, T. (2013). The Uncertain Relationship Between Open Data and Accountability. UCLA Law Review Discourse, 60, 200-214.

Peled, R., Rabin, Y. (2011). The constitutional right to information. Columbia Human Rights Law Review, 42(2), 357-401.

Weber, M. (1982). Ensaios de sociologia. Rio de Janeiro: Livros Técnicos e Científicos.

Weinstein, J., Goldstein, J. (2012). The benefits of a big tent: opening up government in developing countries. UCLA Law Review Discourse, 60, 38-48.

World Wide Web Consortium. (2009). Dados abertos governamentais . Recuperado de http://www.w3c.br/divulgac ao/pdf/dados-abertos-governamentais.pdf.

Yu, H., Robinson, D. (2012). The New Ambiguity of "Open Government. UCLA Law Review Discourse, 59, 178-208. 
Zuccolotto, R., Teixeira, M. (2015). Gestão Social, Democracia, Representação e Transparência: evidências nos estados brasileiros. Revista de Ciências da Administração, 1(3), 79-90.

Zuccolotto, R., Teixeira, M., Riccio, E. (2015). Transparência: reposicionando o debate. Revista Contemporânea de Contabilidade, 12(25), 137-158.

\section{Notas}

I Recuperado de http://www.dados.gov.br/. Acesso em 15 jan. 2019.

II A LAI admite hipóteses de segredo industrial decorrentes da exploração direta de atividade econômica pelo Estado ou por pessoa física ou entidade privada que tenha qualquer vínculo com o poder público (Artigo 22). A lei não aborda os termos para a (re)utilização de dados públicos por terceiros. No âmbito da APF, essa questão foi pautada pelo Decreto $\mathrm{n}^{\circ} 8.777 / 2016$, que estabeleceu a livre utilização dos dados disponibilizados por meio da transparência ativa, cabendo indicar, no caso dos dados protegidos por direitos autorias de terceiros, o detentor e as condições de utilização por ele autorizadas.

III Facebook - Cambridge Analytica data scandal. BBC, 2018. Retrieved from http://www.bbc.com/news/topics/ c81zyn $08881 \mathrm{t} /$ facebook-cambridge-analytica-data-scandal.

IV Lei n ${ }^{\circ} 13.709$, de 14 de agosto de 2018, que dispõe sobre a proteção de dados pessoais.

V No caso brasileiro, isso é especialmente caro, sobretudo quando se leva em consideração os padrões fechados legados por anos de contratação externa, incorporados e institucionalizado na rotina nos processos de órgãos e entidades públicas (Fountain, 2014; Cepik \& Canabarro, 2014). A título de ilustração, a Pesquisa TIC Governo Eletrônico 2017 aponta que $99 \%$ dos órgãos dos Executivo federal disponibilizam em seus websites download de arquivos em formato PDF, um formato não estruturado. Por sua vez, 64, 55 e 45\% disponibilizam, respectivamente, arquivos em formatos DOC, XLS ou PPT, que são padrões proprietários. Formatos abertos aparecem em menor porcentagem: 51\% (XML), 36\% (CSV), $33 \%$ (ODT) e 21\% (RDF) (Núcleo de Informação e Coordenação do Ponto Br, 2017).

VI Decisões de 2015 n 195, 199, 225, 230, 232, 403 e Decisão no 82 de 2016.

VII Decisões de 2016 n 217, 274, 278, 280, 295, 429, 430, 457, 631, 633, 651, 682 e Decisões de 2017 n 6, 37, 42, 282, 283, 369. Em negrito, os deferidos (total ou parcialmente).

\section{BY-NC-ND}

